\title{
FEMINISMOS E ARTES VISUAIS: 0 QUE SE DISCUTE NA PÓS-GRADUAÇÃO BRASILEIRA DO SÉCULO XXI?
}

\author{
FEMINISMS AND VISUAL ARTS: WHAT IS DISCUSSED IN XXI CENTURY BRAZLLIAN POST-GRADUATION
}

\section{RESUMO}

Este artigo tem por objetivo mapear e analisar as discussões sobre os feminismos na produção acadêmica da Pós-graduação brasileira em Artes Visuais. Por meio de uma revisão bibliográfica sistemática, foi explorada a Biblioteca Digital Brasileira de Teses e Dissertações (BDTD), do Instituto Brasileiro de Ciência e Tecnologia (IBICT), no recorte temporal de 2000 a 2019. A análise do conteúdo de vinte e nove dissertações de mestrado e seis teses de doutorado categorizou algumas tendências nessa produção, como: poéticas feministas, leituras feministas, estratégias revisionistas e aproximações feministas. São trabalhos animados por uma epistemologia da diferença, para a qual o mundo e o conhecimento produzido sobre ele não são reduzidos à lógica da identidade de um sujeito universal, mas de subjetividades constrangidas, não raro, por práticas disciplinadoras e de controle, por discursos e saberes instituintes, que se inserem em complexas relações sociais, rompendo um enquadramento normativo-conceitual de gênero e sexualidade.

Palavras-chave: Feminismos. Artes-visuais. Crítica feminista. Poética feminista. Leitura feminista.

\begin{abstract}
This article aims to map and analyze discussion on the feminisms of Brazilian postgraduate academic production in Visual Arts. Through a systematic bibliographical revision, it explores the Brazilian Digital Thesis and Dissertations Library (Biblioteca Digital Brasileira de Teses e Dissertações - BDTD), of the Brazilian Institute of Science and Technology (Instituto Brasileiro de Ciência e Tecnologia - IBICT), in the time period between 2000 and 2019. The content analysis of twenty-nine master theses and six doctoral dissertations has categorized some tendencies in this production, such as: feminist poetics, feminist readings, revisionist strategies and feminist approaches. These are works animated by an epistemology of difference, to which the world, the knowledge produced about it, is not reduced to the logic of a universal subject, but of subjectivities more or less constrained by disciplinary and control practices, by institutional discourse and knowledges, inserted in complex social relations, which break the conceptual normative framing of gender and sexuality.
\end{abstract}

Maria Emilia Sardelich

Doutora em Educação, Professora do Programa Associado de Pós-Graduação em Artes Visuais UFPB/ UFPE.emilisar@hotmail.com

Fernanda S. Nascimento

Doutora em Psicologia, Professora do Mestrado Profissional em Gestão Empresarial do Centro Universitário UniFBV/Wyden. fsardelich@gmail.com 
Keywords: Feminisms. Visual Art. Feminist Critique. Feminist Poetics. Feminist Readings.

\section{Introdução}

Da Declaração dos Direitos da Mulher e da Cidadã, passando pelas Reivindicações dos Direitos da Mulher, das Marias¹, no século XVIII, até a Greve Feminista Internacional, de 8 de março de 2020, o vocábulo feminismo tem sido aplicado em muitos sentidos. Historicamente vinculado às ações das trabalhadoras anarquistas, comunistas, socialistas e sufragistas de finais do século XIX, o feminismo tem sido adjetivado de afrolatinoamericano, branco, burguês, camponês, ciber, comunitário, decolonial, eco, expandido, indígena, institucional, interseccional, liberal, marxista, negro, popular, pós-colonial, pós-humano, radical, trans, entre tantos outros, a depender das necessidades das diversas mulheres do planeta. É por essas muitas diferenças que, neste artigo, utilizamos o termo no plural, feminismos, como o conjunto dos movimentos de ideias, denúncias, proposições, reivindicações, ações autônomas e institucionais, que convergem para a transformação das relações de um sistema social que trata desigualmente pessoas em virtude de seu sexo/gênero/ raça/classe, gerando discriminação, exclusão, iniquidade, opressão, subalternidade, epistemicídios (Carneiro, 2005) e genocídios da alteridade.

No campo das Artes Visuais, desde a década de 1970, podemos encontrar a elaboração de um pensamento feminista, no eixo Estados Unidos/Inglaterra, tanto na produção artística quanto na crítica de arte, como o fértil texto de Linda Nochlin e seus questionamentos sobre uma História da Arte androcêntrica (Nochlin, 2016). Desde então, estratégias revisionistas têm incluído nomes de mulheres esquecidas pelos canônicos manuais de uma História da Arte que, como nos fez ver Griselda Pollock (Pollock, 2013), apresenta uma produção artística que não tem sido reflexo do mundo, mas se constitui como um conjunto de práticas significantes, pavimentando as concepções acerca da categoria mulher. Ao longo de mais de quatro décadas, artistas e críticas inspiradas nos feminismos vêm colaborando para a construção de múltiplas histórias da arte, que sejam capazes de dar visibilidade às formas de produção e opressão pelas quais esse sistema opera, como também as estratégias que possam levar as pessoas, que conformam o mundo da arte, a pensar sobre gênero, raça e sexualidade, a fim de torná-lo mais inclusivo (REILLY, 2019). A crítica feminista desconstrói o cânon - o gênio masculino, branco, heterossexual, da Europa ou dos Estados Unidos - ao propor uma leitura que considera o gênero da autoria, as questões relativas ao papel da mulher como produtora de significados e não somente portadora de significados produzidos pelos homens artistas. Uma leitura que parte do ponto de vista das mulheres, uma interpretação das imagens da arte como o

1 Fazemos referência à francesa Marie Gouze (1748 - 1793), também conhecida como Olympe de Gouges, autora da Declaração dos Direitos da Mulher e da Cidadã, de 1791, eà inglesa Mary Wollstonecraft (17591797), autora da Reivindicação dos Direitos da Mulher, de 1792. 
espaço em que se articulam significados sobre as posições sociais de mulheres e homens ao longo dos séculos.

No contexto latino-americano, Andrea Giunta (2018) explica que, apesar das especificidades de cada um dos países, do lugar das mulheres em cada sociedade, bem como dos discursos e políticas em debate na época, as relações entre arte efeminismos, a partir da década de 1970, foram reprimidas em quase todos os países do cone sul por duas razões principais. A primeira deve-se ao descrédito das formações políticas da esquerda pela militância feminista, por compreender que esta reivindicação debilitaria a construção de uma frente comum que aspirava à revolução. A segunda é consequência da violência exercida pelas ditaduras militares contra toda e qualquer atividade política. Embora esses dois fatores tenham refreado a expressão feminista, muitas artistas, que não se autoidentificaram como feministas, desenvolveram um sistemático processo de investigação focado no corpo e nas violências às quais, culturalmente, as mulheres têm estado submetidas.

No Brasil, Heloísa Buarque de Hollanda (2018) indicou a refratariedade do nosso contexto cultural, ao discutir as diferenças no campo artístico. A mencionada autora salienta o fato de que poucas artistas brasileiras se sentem confortáveis quando se autonomeiam feministas, entendendo tal situação como um sintoma da ambiguidade no trato das questões raciais e sexuais, bem como a rejeição machista do patriarcado brasileiro. Considera que a autodenominação feminista só ficou confortável no Brasil a partir de 2010 e, especialmente, a partir de 2015, quando o ativismo feminista ganhou maior visibilidade nas manifestações de mulheres contra o Projeto de Lei 5069/2013, que visava dificultar o acesso de vítimas de estupro aos cuidados médicos.

Ana Mae Barbosa (2010) expõe como algumas artistas brasileiras do século XIX e início do XX tiveram certo reconhecimento à época, ganharam medalhas e até prêmios de viagens, mas foram apagadas dos livros de História da Arte. Afirma, ainda, que a celebrada igualdade no sistema da arte no Brasil é descartada pela ausência de memória da produção de mulheres. Apesar dessas dificuldades, pesquisadoras como Ana Paula Simioni (2008), Luana Saturnino Tvardovskas (2015), Roberta Barros (2016) e Madalena Zaccara (2017), têm dado visibilidade a muitas outras artistas, nomes que nem sempre estão registrados nos compêndios de História da Arte, contestando a retórica de sucesso e de suposta igualdade das mulheres na arte brasileira.

A controversa teoria e prática da democratização dos acessos ao sistema da arte, da representatividade, visibilidade e da diversidade de grupos humanos que compõem a sociedade brasileira é denunciada por Renata Felinto dos Santos (2019), que destaca como a invisibilidade desses grupos "se transmuta em violência da subcidadania que, por sua vez, se converte em sub-representação" (SANTOS, 2019, p. 342). As pesquisadoras Andrea Senra Coutinho e Luciana Gruppelli Loponte (2015) questionam o sentido de discutir a relação entre artes visuais e feminismos no século XXI e os possíveis efeitos dessa discussão nas práticas contemporâneas do ensino de arte. Consideram, ainda, que este é um tema quase invisível em relação à arte e às práticas docentes, além da escassa produção teórica a respeito, sobretudo em língua 
portuguesa. Apontam a rejeição das expressões "artista feminista" e "arte feminista" como herança dos contraproducentes clichês das primeiras representações gráficas feitas sobre as feministas de finais do século XIX e inícios do XX, como mulheres dominantes, histéricas, amargas, abruptas, agressivas, feias as quais restaria apenas a opção de entregar-se à uma causa política e à masculinização. Para as autoras, a categoria mulher na produção artística não garante uma relação com o feminismo, sendo necessária a atenção para que, nessas análises, "não ocorra uma simples projeção, ou seja, ver o feminismo onde se deseja, e não onde ele de fato está" (Coutinho \& Loponte, 2015, p. 185).

É a partir dessas observações iniciais, que nos propusemos a ver onde os feminismos se encontram e se reconhecem como tal na produção acadêmica dos Programas de Pós-graduação em Artes Visuais. Sabemos que algumas pesquisas sobre Arte têm sido realizadas em outros Programas de Pós-Graduação, como, por exemplo, no Instituto de Filosofia e Ciências Humanas (IFCH), da Universidade Estadual de Campinas, sob a orientação da Professora Doutora Margareth Rago, que resultou na publicação de Tvardovskas (2015); na Faculdade de Ciências e Letras da UNESP, no Programa de Psicologia, o trabalho de Roberta Stubs (2015), sob a orientação do Professor Doutor Fernando Silva Teixeira Filho; na Faculdade de Educação, da Universidade de São Paulo, sob a orientação de Celso Fernando Favaretto, o trabalho de Trizoli (2018).

Apesar de ser possível encontrar relações entre o pensamento feminista e a Arte em outras áreas do conhecimento, nosso interesse se encontra na produção específica em Artes Visuais. Por essa razão, o recorte que se apresenta neste artigo refere-se à coleta, organização, classificação e à análise das dissertações e teses defendidas no Brasil, entre os anos de 2000 e 2019. Para tanto, organizamos a exposição em quatro partes: a primeira descreve o processo de levantamento bibliográfico realizado; a segunda revela os achados da pesquisa. A análise desses achados se realiza na terceira parte; e, por fim, a quarta tece a conclusão alcançada até o momento.

\section{Os caminhos da pesquisa}

Consideramos a revisão bibliográfica sistemática como um caminho possível para esta investigação, a fim de mapear a discussão sobre os feminismos nos programas de pós-graduação brasileiros em Artes Visuais. Essa revisão explorou a Biblioteca Digital Brasileira de Teses e Dissertações (BDTD), do Instituto Brasileiro de Ciência e Tecnologia (IBICT), pelo fato de essa base de dados disponibilizar os trabalhos completos produzidos na pós-graduação do país. Como apontam Moraes e Oliveira (2010), dissertações e teses são indicadores de avaliação na produção científica de uma área, além de ser subsídio para a política de ensino e pesquisa. Por meio da observação desses trabalhos, é possível localizar as áreas do conhecimento em expansão, bem como as lacunas de pesquisa no âmbito institucional nacional. 
Um dos primeiros desafios enfrentados neste processo foi a definição dos descritores para a coleta dos trabalhos no banco de dados. Esse desafio refere-se tanto à questão da especialização do conhecimento e as relações de poder que a envolvem, quanto aos aspectos teórico-metodológicos. Ponderamos que não incluiríamos o descritor gênero, pelo fato de esse campo específico de estudos contar com pesquisadores que "nega $(\mathrm{m})$ a ligação de suas pesquisas com o feminismo, como se gênero fosse uma categoria neutra, apenas denominativa" (Scavone, 2008: 173). Como nosso interesse é mapear a contribuição da crítica feminista para as Artes Visuais, isto é, verificar o ponto onde os feminismos se encontram e se reconhecem como tal, optamos somente pelas palavras feminismo(s), feminista(s), presentes no título, resumo e ou palavras-chaves das dissertações e teses dos programas em Artes Visuais. Consideramos que vários trabalhos produzidos no recorte delimitado poderiam se relacionar com a crítica feminista como, por exemplo, Romero (2003), Bortolin (2006), Xavier (2008), que dissertam sobre suas poéticas a partir das metáforas corpo, carne, entranhas, ninho, casa, cidade; porém, em nenhum momento, essas autoras indicam que estas questões podem ser tratadas a partir do pensamento feminista, nem enquadraram seus trabalhos nessa perspectiva. Por conseguinte, esse tipo de produção, que relaciona o feminino ou a poética artística à divindade, sacralidade, maternidade, inocência, maturidade, sensualidade, ideal e aos padrões de beleza, sem referência explícita aos feminismos, não fez parte de nossa coleta.

Para alcançar o objetivo de descrever os questionamentos, enquadramentos teóricos e tendências desta pesquisa, realizamos uma análise de conteúdo. Bardin (1979) adverte que não existe nenhum procedimento "pronto" para o uso em análise de conteúdo, apenas algumas regras de base, uma vez que o procedimento adequado a cada pesquisa tem de ser reinventado na construção da própria investigação. Dentre as regras básicas, destaca-se o processo de categorização, que pode ser definido como uma operação de classificação dos elementos constitutivos de um conjunto por diferenciação. A categorização a que se chegou, na análise do conjunto dos trabalhos, não foi definida, a priori, mas emergiu da leitura do próprio conjunto.

Consideramos que a produção deste artigo de revisão, derivado da produção acadêmica analisada, torna-se relevante por permitir um estudo minucioso do conhecimento produzido, constatar a trajetória da temática nos Programas de Pósgraduação em Artes Visuais, indicar uma bibliografia em língua portuguesa e avistar outras possibilidades de investigação.

\section{Os achados da pesquisa}

Finalizada a coleta de dados em dezembro de 2019, localizamos trinta e cinco trabalhos, sendo vinte e nove dissertações de mestrado e seis teses de doutorado. Apesar de o recorte temporal desta pesquisa restringir-se aos anos de 2000 a 2019, 
encontramos apenas produções que atendem aos nossos critérios entre os anos de 2007 e 2019.

Quadro 1. Produção acadêmica localizada

\begin{tabular}{|c|c|c|c|c|c|}
\hline ANO & PROGRAMA & DISS. & TESE & $\begin{array}{l}\text { TOTAL } \\
\text { IES }\end{array}$ & $\begin{array}{c}\text { TOTAL } \\
\text { REGIÃOO }\end{array}$ \\
\hline \multirow[t]{7}{*}{2019} & Programa em Arte e Cultura Visual - UFG & $\mathbf{1}$ & & $\mathbf{1}$ & $\mathrm{CO}=1$ \\
\hline & Programa em Artes - UFPA & 2 & & 2 & $\mathbf{N}=\mathbf{2}$ \\
\hline & Programa em Artes - UFES & 1 & & $\mathbf{1}$ & \multirow{2}{*}{$S E=2$} \\
\hline & Programa em Artes - UFMG & $\mathbf{1}$ & & $\mathbf{1}$ & \\
\hline & Programa em Artes Visuais -UFRGS & 1 & & $\mathbf{1}$ & \multirow{2}{*}{$S=2$} \\
\hline & Programa em Artes Visuais - UFSM & 1 & & 1 & \\
\hline & & & & & o7 \\
\hline \multirow[t]{7}{*}{2018} & Programa de Pós-graduação em Artes - UFC & $\mathbf{1}$ & & 1 & \multirow{2}{*}{$\mathrm{NE}=2$} \\
\hline & Programa A. em Artes Visuais UFPB/UFPE & $\mathbf{1}$ & & 1 & \\
\hline & Programa em Artes - UFJF & 1 & & 1 & \multirow{3}{*}{$\mathrm{SE}=4$} \\
\hline & Programa em Artes - UNESP & & 1 & 1 & \\
\hline & Programa I. em Estética e História da Arte - USP & 2 & & 2 & \\
\hline & Programa em Artes Visuais -UFPel & 1 & & 1 & $S=1$ \\
\hline & & & & & o7 \\
\hline \multirow[t]{6}{*}{2017} & Programa em Arte e Cultura Visual - UFG & 1 & 1 & 2 & $\mathrm{CO}=2$ \\
\hline & Programa A. em Artes Visuais UFPB/UFPE & $\mathbf{1}$ & & $\mathbf{1}$ & $\mathrm{NE}=1$ \\
\hline & Programa em Artes - UFMG & & 1 & 1 & \multirow{2}{*}{$\mathrm{SE}=\mathbf{2}$} \\
\hline & Programa em Artes - UNESP & $\mathbf{1}$ & & 1 & \\
\hline & Programa em Artes Visuais - UFRGS & 1 & & 1 & $S=1$ \\
\hline & & & & & 06 \\
\hline \multirow[t]{2}{*}{2015} & Programa A. em Artes Visuais UFPB/UFPE & 1 & & 1 & $\mathrm{NE}=1$ \\
\hline & & & & & o1 \\
\hline \multirow[t]{2}{*}{2014} & Programa em Arte e Cultura Visual - UFG & 1 & 1 & 2 & $\mathrm{CO}=2$ \\
\hline & & & & & 02 \\
\hline \multirow[t]{4}{*}{2013} & Programa em Artes - UERJ & $\mathbf{1}$ & & 1 & \multirow{3}{*}{$\mathrm{SE}=3$} \\
\hline & Programa em Artes Visuais - UNICAMP & & 1 & 1 & \\
\hline & Programa em Artes Visuais -USP & 1 & & $\mathbf{1}$ & \\
\hline & & & & & 03 \\
\hline \multirow[t]{3}{*}{2012} & Programa em Arte e Cultura Visual - UFG & $\mathbf{1}$ & & 1 & $\mathrm{CO}=1$ \\
\hline & Programa em Artes - UFMG & $\mathbf{1}$ & & 1 & $\mathrm{SE}=1$ \\
\hline & & & & & 02 \\
\hline \multirow[t]{2}{*}{2011} & Programa I. em Estética e História da Arte - USP & 1 & & 1 & $\mathrm{SE}=1$ \\
\hline & & & & & o1 \\
\hline \multirow[t]{2}{*}{2010} & Programa em Artes - UNESP & $\mathbf{1}$ & & 1 & $\mathrm{SE}=1$ \\
\hline & & & & & 01 \\
\hline \multirow[t]{4}{*}{2009} & Programa em Artes - UNESP & 1 & & 1 & $\mathrm{SE}=1$ \\
\hline & Programa em Artes Visuais - UFRGS & & $\mathbf{1}$ & $\mathbf{1}$ & \multirow{2}{*}{$S=2$} \\
\hline & Programa em Artes Visuais - UFSM & 1 & & 1 & \\
\hline & & & & & 03 \\
\hline \multirow[t]{2}{*}{2008} & Programa em Arte e Cultura Visual - UFG & 1 & & 1 & $\mathrm{CO}=1$ \\
\hline & & & & & o1 \\
\hline \multirow[t]{2}{*}{2007} & Programa em Arte e Cultura Visual - UFG & 1 & & 1 & $\mathrm{CO}=1$ \\
\hline & & & & & o1 \\
\hline TOTA & & & 06 & & \\
\hline
\end{tabular}


A partir desses achados, notamos um incremento nessa produção a partir de 2015, dado que podemos relacionar à observação feita por Holanda (2018), acerca da denominação feminista ainda ser incômoda no Brasil e como o recente ativismo feminista ganhou maior visibilidade a partir de 2015 .

Em relação aos polos de produção desse conhecimento, a região Sudeste apresenta o maior quantitativo, com quinze trabalhos. Dentre esses, duas produções foram orientadas pela Professora Doutora Geralda Mendes F. S. Dalglish, do Programa de Pós-graduação em Artes, do Instituto de Artes, da Universidade Estadual Paulista Júlio de Mesquita Filho (UNESP), sendo uma dissertação de mestrado e uma tese produzidas pela mesma acadêmica Flávia Leme de Almeida (Almeida, 2009; Almeida, F. 2018). A região Centro-Oeste ocupa a segunda posição com oito trabalhos, todos produzidos no Programa de Pós-graduação em Arte e Cultura Visual, da Faculdade de Artes Visuais (FAV), da Universidade Federal de Goiás (UFG). No meio das produções, encontram-se seis dissertações e duas teses; destas, três trabalhos, sendo duas dissertações e uma tese, foram orientados pela Professora Doutora Rosa Maria Berardo. Na terceira posição temos a região Sul, com seis trabalhos e a liderança dessa produção recai sobre o Programa de Pós-Graduação em Artes Visuais, do Instituto de Artes (IA), da Universidade Federal do Rio Grande do Sul (UFRGS), com duas dissertações e uma tese orientadas por diferentes doutores. A região Nordeste ocupa a quarta posição com quatro trabalhos, sendo três dissertações do Programa Associado de Pós-Graduação em Artes Visuais, da Universidade Federal da Paraíba (UFPB) e Universidade Federal de Pernambuco (UFPE), orientadas por diversos doutores. Por fim a região Norte, com duas dissertações orientadas por diferentes doutores do Programa de Pós-Graduação em Artes, do Instituto de Ciências da Arte (ICA), da Universidade Federal do Pará (UFPA).

A análise do conjunto dos 35 trabalhos produzidos revelou uma profusão de 108 palavras-chaves que, dentre estas, somente 15 apresentaram mais de uma ocorrência, a saber: feminismo, 13 vezes; gênero, oito; arte contemporânea, seis; fotografia, cinco; arte, quatro; identidade, quatro; arte feminista, três; arte e cultura, duas; artes visuais, duas; corpo, duas; crítica feminista, duas; educação, duas; mulheres artistas, duas; performance, duas; processo criativo, duas. Consideramos que a abundância de palavras-chaves desses trabalhos deve-se ao fato de que tanto os feminismos quanto as Artes Visuais estão atravessados por conceitos de vários campos de estudo e podem articular seus argumentos a partir de diferentes premissas, sejam ontológicas, epistemológicas ou políticas.

Dos 35 trabalhos localizados, 27 assumem os feminismos e a crítica de arte feminista pela constatação e contestação do cânon e práticas sexistas do sistema da arte, pela revisão da historiografia da arte, como também pela inclusão da perspectiva de gênero, afastando-se de um posicionamento essencialista de uma suposta estética e ou estilo feminista, situando-se na compreensão de que as mulheres produzem significados a partir do lugar que ocupam no mundo, mais ou menos subordinado, a depender dos fatores sociais, políticos e culturais. Consideramos que os demais trabalhos tangenciam os feminismos, por situarem historicamente o movimento 
feminista e as teorias de gênero, porém sem discutir as opressões vividas pelas mulheres e a produção artística feminina como uma controvérsia da estrutura patriarcal. Por essa razão, categorizamos esses trabalhos como aproximações feministas. Apresentaremos a análise realizada a partir da identificação explícita com a crítica feminista. Quantitativamente, foi possível categorizar as seguintes estratégias dentre os 27 trabalhos: poéticas feministas - nos quais a crítica feminista impulsiona a poética, o processo criativo das pesquisadoras, com 13 trabalhos; leituras feministas - nos quais a crítica feminista sustenta a leitura da produção artística de mulheres, também com 13 trabalhos; estratégia revisionista, no qual se reabilita mulheres artistas, com um trabalho.

\section{Poéticas feministas}

Denominamos de poéticas feministas as investigações em que a crítica feminista provoca o criar/pensar individual e ou coletivo, animado pelo encontro com a produção de outras artistas mulheres, acolhidas como referências que entrelaçam vidas e processos artísticos. No meio desses treze trabalhos, nove tratam da poética individual das autoras, como os de: Almeida (2009); Almeida F. (2018); Aniceto (2018); Garcia (2019); Gonçalves (2018); Grill (2018); Iório (2017); Santos D. (2019); Souza (2012). As poéticas de Castañeda Demesa (2019), Castro (2013), Santos C. (2019) e Sousa (2019) apresentam um caráter mais ativista, enfatizando a criação coletiva. Embora seja possível encontrar referências históricas, mais especificamente sobre as guildas medievais e a produção artística coletiva, é a partir da última década do século XX e início do XXI que a mesma se afirma. A proposta de criação coletiva desloca ideias arraigadas sobre o cânon e o talento individual, que tem vigorado desde a Renascença. A concepção de criatividade individual ainda é muito arraigada no sistema da arte e tem sido contestada por expressivos coletivos artísticos desde meados de 1980, a exemplo do Guerilla Girls e outros grupos feministas. O ponto focal desses coletivos é o ativismo, por meio do qual os "trabalhadores das ideias podem encontrar meios alternativos de produzir conhecimento e arte” (MADEIRA, 2016, p. 5), além de manter certa independência em relação às instituições e transformar as condições de produção cultural nas sociedades atuais.

Em relação aos feminismos, os trabalhos se caracterizam por uma abordagem histórica, que parte da denominada, didaticamente, segunda onda feminista sendo a matriz de referência O Segundo Sexo, de Simone de Beauvoir (1908-1986), indicada em diferentes edições, e que nas referências deste artigo optamos pela de 1970. A linha do tempo que caracteriza a abordagem histórica desses trabalhos destaca o slogan "o pessoal é político", ou seja, o que acontece na vida pessoal, nas relações entre os sexos, no âmbito doméstico e não doméstico, não podem ser interpretados de modo isolado, e vai deslocando-se pelos estudos de gênero, sendo as referências mais citadas as de Joan Wallach Scott (1995), Judith Butler (2003), Teresa de Lauretis 
(1994), Donna Haraway (2000), Rosi Braidotti (2002), Paul Beatriz Preciado (2008). Em relação aos feminismos no Brasil, foram apontados os trabalhos de Ana Alice Alcantara Costa (2009), Branca Moreira Alves e Jacqueline Pitanguy (1991); Heloisa Buarque de Hollanda (1994), Guacira Lopes Louro (2004, 2010), Margareth Rago (1998), Maria Amélia de Almeida Teles (1993). Essas referências sinalizam a compreensão de que o processo de subjetivação social não se desliga do gênero, sendo este atravessado por diversos eixos de opressão, na interseccionalidade das categorias classe, raça, sexualidade.

Nessa esteira do debate, algumas pesquisadoras mencionam feminismos mais específicos como "ecofeminismo" (Almeida F., 2018: 63); "feminismos negros plurais, tanto do Brasil como da África e da América Latina” (Garcia, 2019: 48), a partir de referências como: Angela Davis (2017), bell hooks (2018), Carla Akotirene (2018), Chimamanda Ngozi Adichie (2018), Djamila Ribeiro (2017), Gloria Anzaldúa (2009), Maya Angelou (2018), Rita Laura Segato (2016), Sueli Carneiro (2001). Castañeda Demesa (2019) indica, ainda, o feminismo comunitário de Seyla Benhabib (2006) e Iório (2017) reconhece que sua aproximação aos feminismos aconteceu nas redes sociais, através da popularização das hashtags \#PrimeiroAssedio e \#meuamigosecreto, em 2015, e que a partir desse contato virtual se aproximou dos ciberfeminismos e da publicação de Claudia Mayer (2017).

Sobre a crítica de arte feminista, as pesquisadoras indicam que essa bibliografia ainda é pouco acessível no Brasil, principalmente em português, pois são fontes escassas e recentes. As referências mais citadas são as estadunidenses e inglesas: Amelia Jones (2011), Judy Chicago (2017), Linda Nochlin (2016) Griselda Pollock (2013), Laura Mulvey (1983), Martha Rosler (2011); também marcam presença: Ana Mae Barbosa (2010), Ana Paula Simioni (2008), Aracy Amaral (2006), Filipa Lowndes Vicente (2012), Luana Saturnino Tvardovskas, (2015), Maria Ruído (2005), Marián Lopes Fernandez Cao (1991) Mónica Mayer (1999), Nelly Richard (2002), Patrícia Mayayo (2003), Roberta Barros (2016), Rocio de la Villa (2013), Uta Groesnick (2005).

As artistas que impulsionam a poética das pesquisadoras e mencionadas nesses trabalhos, foram: Amor Munõz (1979); Ana Mandieta (1948 - 1985); Ana Maria Maiolino (1942); Ana Teresa Barboza (1981); Anette Messager (1943); Anni Albers (1899 - 1994); Cayce Zavageria (1971); Celeida Tostes (1929 - 1995); Cindy Sherman (1954); Emilie Louise Floge (1874 - 1952); Frida Kahlo (1907 - 1954); Graciela Olio; Gunta Stolz (1897 - 1983); Judy Chicago (1939); Kukuli Velarde (1962); Louise Bourgeois (1911 - 2010); Marina Abramović (1946); Marta Minjuin (1943); Mónica Mayer (1954); Niki de Saint Phalle (1930 - 2002); Rebeca Horn (1944); Rosana Paulino (1967); Ruby Rumié (1958); Sofia Borges (1984); Sonia Gomes (1948); Tracey Emin (1963).

As treze pesquisadoras anteriormente indicadas recolhem afinidades poéticas entre os fazeres das artistas mencionadas, com as quais se vinculam e pensam sobre suas formas de ver a relação da mulher com a terra; a relação dos seres com suas procedências e descendências; os processos de transformação dos corpos; os cuidados de si e a repressão dos castigos corporais; a violação dos corpos a partir de distintas formas de violência física, psicológica, tecnológica; o corpo mercadoria, 
classificado a partir de categorias como sexo, cor de pele, idade, nacionalidade; o mercado de imagens eróticas e pornográficas; a sexualidade; a divisão sexual do trabalho doméstico; a objetificação dos corpos femininos, como desfrute, temor e decadência; o feminicídio.

Os trabalhos de investigação enumerados referem-se incisivamente à dificuldade para localizar registros sobre mulheres artistas, nos mais diferentes momentos da história da arte, como também o investimento de pesquisadoras mulheres sobre artistas antepassadas, sinalizando que o protagonismo feminino ganha visibilidade por meio do trabalho de mulheres que vão além das práticas sexistas do sistema da arte. Apontam que é por meio da participação empoderada de mulheres pesquisadoras, artistas, curadoras, professoras, críticas que será possível a emergência de subjetividades menos constrangidas, assim como outras formulações de estruturas de poder, representações e apresentações do feminino. Indicam que, apesar da participação das mulheres no sistema da arte, isso possa ser interpretado como uma segmentação ou estereotipificação; essa agência tende a criar novos espaços, como também desconstruir a categoria "mulher universal" e estimular um discurso menos binário.

\section{Leituras feministas}

As pesquisas de Almeida I. (2018), Arruda (2013), Branco Cornish (2018), Dimambro (2018), Gallo (2015), Marchi (2009), Mattiolii (2018), Pacheco (2019), Ribeiro (2012), Santos (2014), Saraiva (2017), Souza (2019), Trizoli (2011), foram categorizadas como leituras feministas, por buscarem fundamentação na crítica feminista para interpretar a produção artística de mulheres que não necessariamente se identificaram e/ou declararam afiliação aos feminismos. Em geral, esses trabalhos buscam paralelismos com artistas já legitimadas pelo sistema da arte, como Adrian Piper (1948), Carolee Schneemann (1939 - 2019), Faith Wilding (1943), Lygia Clark (1920 - 1988), Lygia Pape (1927 - 2004), Marina Abramovic (1946), Nancy Spero (1926 - 2009), Paula Modersohn-Becker (1876 - 1907) Shigeko Kubota (1937- 2015), Suzanne Valadon (1865 - 1938), Yoko Ono (1933), contribuindo para a desconstrução de estereótipos que dificultam a compreensão dos feminismos nas Artes Visuais. As artistas interpretadas nessas leituras foram: Aleta Valente (1986), Amalia Ullman (1989), Andressa Ce. (1999), Anna Bella Geiger (1933), Anna Maria Maiolino (1942), Barbara Kruger (1945), Cindy Sherman (1954), Fernanda Magalhães (1962), Francesca Woodman (1958 - 1981), Gretta Sarfaty (1954), Iole de Freitas (1945), Laís Pontes, Laurie Simmons (1949), Lenora de Barros (1953), Luisa Dőor (1989), Luiza Prado (1988), Marta Cezaria (1956), Martha Rosler (1943), Martine Gutierrez (1989), Nakeya Brown (1988), Orlan (1947), Paula Rego (1935), Petra Collins (1992), Polly Nor (1989), Regina Vater (1943), Sonia Andrade (1935), Teresinha Soares (1937), Wanda Pimentel (1943-2019). 
Esses treze trabalhos realizados revelam algumas das muitas lacunas existentes na historiografia da arte no Brasil e o investimento das pesquisadoras em visibilizar o protagonismo das artistas mulheres. Em relação aos feminismos, a abordagem nesses trabalhos também é histórica, não se diferenciando da linha do tempo e das referências indicadas nos estudos categorizados como poética feminista. Como aponta a pesquisadora Branco Cornisch (2018), o seu trabalho - consideramos que os demais também - colabora com a escrita de uma história da arte brasileira a partir da trajetória e obras de algumas mulheres artistas, ou seja, aquelas que são "cooptadas pelo sistema da arte" (MAYAYO, 2003), as mulheres brancas, de classe média alta, com acesso à educação e ao circuito artístico, provavelmente um perfil muito próximo das pesquisadoras que também puderam produzir essas interpretações. Neste ponto, cabe destacar o diferencial da tese de Santos (2014), que analisa o trabalho de Marta Cezaria (1956), cuja trajetória se confunde com a história da organização das mulheres negras no município de Goiânia (GO), inscrevendo-se na tradição das religiões de matriz africana que reconhece a liderança feminina. $\mathrm{O}$ filme ... se eu fosse uma flor..., primeira produção cinematográfica de Marta Cezaria, evidencia a sua condição de mulher negra, política, religiosa e trabalhadora, em uma poética visual marcada pela ação coletiva, que se apresenta como um mosaico identitário, multifacetado, formado por diferentes pontos de vista das mulheres negras representadas. Santos (2014) considera que Marta Cezaria produz muito mais do que um documentário; promove, na verdade, um manifesto com a intenção produzir estados de consciência de gênero, raça e empoderamento, considerando, concomitantemente, a subjetividade/coletividade através de suas relações políticas.

Nessas treze investigações, as leituras produzidas alicerçam uma visão brasileira, latino-americana, na crítica de arte feminista ainda impregnada pela visão eurocêntrica. Para a construção do olhar brasileiro sobre o próprio contexto social, os trabalhos de Cynthia Andersen Sarti (1998, 2004) e De Marco; Schimidt (2003) são referências fundamentais, pois destacam a origem social das militantes feministas brasileiras nas camadas médias e intelectualizadas que, apesar de informadas sobre os movimentos feministas dos Estados Unidos e da Europa, estavam sob fogo cruzado da direita - acusadas como imorais e perigosas -, da esquerda - vistas como reformistas burguesas - e de um sistema de arte sexista, impregnado pela falsa retórica da participação igualitária. Os trabalhos que categorizamos como leituras feministas contribuem para a construção de um relato historiográfico a partir da experiência de mulheres artistas e pesquisadores, a partir "das margens, da construção miúda, da gestão do detalhe, que se expressa na busca de uma nova linguagem, ou na produção de um contradiscurso" (Rago, 1998, p. 3). 


\section{Estratégia revisionista}

Categorizamos o trabalho de Rodrigues (2010) como uma estratégia revisionista (REILLY, 2019), devido a sua proposta de retomar nomes de mulheres da história, algumas esquecidas, como, por exemplo, as artistas mulheres que ocuparam as páginas da revista Klaxon, publicada em São Paulo entre 1922 e 1923. Esta investigação reabilita artistas como Agnes Ayres (1898-1940), Anita Malfatti (1889-1963), Antonietta Rudge (1885-1974), Bebe Daniels (1901-1971), Céline Arnauld (1893-1952), Gloria Swanson (1899-1983), Guiomar Novaes (1894-1979), Perola White (Pearl White) (1889-1938), Sarah Bernhardt (1844-1923), Tarsila do Amaral (18861973) e Zina Aita (1900-1967).

Em relação aos feminismos, o trabalho de Rodrigues (2010) também apresenta uma abordagem histórica restrita ao contexto do Brasil, entre o final da década de 1910 e 1930, coerente com o seu recorte espacial e temporal. Desse modo, destacase a organização da Federação Brasileira pelo Progresso Feminino (FBPF), fundada pela iniciativa de Bertha Lutz (1894 - 1976), entre outras, em 1922, mesmo ano da celebrada Semana de Arte Moderna, em São Paulo. Indica que, apesar da profusão de publicações da imprensa brasileira destinadas à mulher nas duas primeiras décadas do século XX, abundam artigos irônicos, crônicas e charges sarcásticas, ao se referirem aos movimentos de emancipação feminina. Ana Paula Simioni (2006), Mary del Priore (2007) e Susan Besse (1999) foram as referências para o estudo das artistas da época. A estratégia de Rodrigues (2010) oferece uma compreensão mais contextual do relato histórico, permitindo uma leitura desde outras perspectivas, retificando vazios, ausências nos arquivos, funcionando como uma espécie de efemérides, homenagem às mulheres em datas assinaladas.

\section{Aproximações feministas}

Consideramos os trabalhos de De Martino (2009), Mafra (2017), Marques Filho (2007), Stanick (2017), Silva (2008), Silva (2013), Oliveira (2014) e Ribeiro (2017) como estratégias de aproximação aos feminismos, por abordarem o movimento feminista e as teorias de gênero, sem focalizar as opressões vividas pelas mulheres no debate da produção artística. Ao se referirem aos feminismos, o fazem por meio de uma abordagem histórica sucinta, como um antecedente dos estudos de gênero. Como salienta Margareth Rago (1998), a teoria de gênero também abriu a possibilidade da constituição de estudos sobre os homens, em um campo teórico renovado e redimensionado sobre a masculinidade e os homens, não mais percebidos como sujeitos universais. Destarte, os trabalhos categorizados como aproximações feministas também discutem a produção de artistas homens e ou representações dos corpos andrógenos, femininos, masculinos, além de temas associados aos feminismos, como as sexualidades, as confissões e o humor. 
De Martino (2009) aborda a emergência da confissão na arte contemporânea, caracterizada como uma prática que consiste em anunciar o testemunho de um desvio, revelando-se como uma experiência diversa do saber cognitivo e da informação. Investiga as origens da confissão em diversos momentos da História Ocidental, apresentando artistas como Andy Warhol (1928 - 1987), Beth Moysés (1960), Claude Cahun (1894 - 1954), Karen Finley (1956), Marcel Duchamp (1887 1968), Nan Goldin (1953), Tracey Emin (1963). Aborda a temática da confissão a partir do conceito de circonfissão, cunhado por Jacques Derrida (1930 - 2004). Compreende a circonfissão como uma reunião da confissão com a circuncisão, construindo um conceito em que confissão se torna uma espécie de recostura, uma cicatriz. Conclui que a arte contemporânea explora essa via negativa que é cristalizada pela confissão, operando através da intimidade e conduzindo o relato a uma sensação de abandono, provocando o prazer ou o gozo sem excluí-los.

O humor, estudado a partir da Filosofia e da Psicanálise, é o centro de interesse de Mafra (2017), que tangencia os feminismos ao indicar que as artistas que se identificaram com a "causa feminista", como Judy Chicago (1930), Melanie Bonajo (1978) ou o coletivo Guerrilla Girls, fazem uso do humor. Afirma que a produção artística das artistas estadunidenses na década de 1970 está repleta de humor, com a construção da Herstory, uma narrativa paródica de History, um trocadilho que indica a versão de um novo ponto de vista, o feminino, que inclui tecidos, maquiagens, absorventes, laços e outros materiais, que começam a fazer parte da linguagem artística, assim como os trabalhos manuais aprendidos de suas gerações anteriores. Além da produção dessas artistas, também indica obras de Andres Serrano (1950), Héctor Zamora (1974), Javier Téllez (1969), Luis Camnitzer (1937), Nadín Ospina (1960), Paul McCarthy (1945), Paulo Nazareth (1977), Piero Manzoni (1933 - 1963), Win Delvoye (1965).

Considerando o impacto das novas tecnologias de comunicação sobre as manifestações ativistas contemporâneas, com ampla repercussão mundial, Silva (2013) procurou investigar como os grupos ativistas utilizam e relacionam mídias tradicionais e digitais. Seu estudo não se volta para os feminismos, mas para a comunicação, mais especificamente para o uso da imagem pelos grupos feministas Femen e Pussy Riot. Situa historicamente as relações entre performance e feminismo, porém não aprofunda o debate, ressaltando que a estratégia do uso do corpo feminino nunca foi um consenso entre as feministas, pois pesa o argumento de que a exploração desse corpo poderia, na verdade, reforçar a objetificação do corpo feminino, já disseminada na sociedade.

O foco do trabalho de Marques Filho (2007) incide no debate sobre as relações entre a experiência homossexual, teoria queer e educação. Aborda historicamente o movimento feminista como antecedente da teoria queer, relacionando-a com a estética camp. Fundamenta-se em Susan Sontag (1987) para argumentar que a representação do andrógeno seria uma das grandes imagens da sensibilidade camp. Destaca artistas que representaram o nu masculino, como Alair Gomes (1921 - 1992), F. Holand Day (1864 - 1933), Hudinilson Junior (1957 - 2013), 
Robert Mapplethorpe (1946-1989), Wilhem von Gloden (1856-1931). Com essa rede conceitual, ele trabalha as histórias de vida de dois artistas goianos que se mantém no anonimato por tratarem do tabu da sexualidade. $\mathrm{O}$ autor questiona as interdições existentes no ambiente escolar em torno da sexualidade e como os estudos da Cultura Visual poderiam ampliar essa discussão, explorando temas como: a apropriação do corpo masculino na arte contemporânea; o corpo como território de contestação política e ideológica; a arte/educação como forma de transformação e intervenção nos modos de ver, sentir e agir; a teoria queer como posicionamento que busca desestruturar as convenções e as normas.

Próximo da discussão sobre as interdições existentes no contexto escolar, Oliveira (2014) indaga sobre a ausência de discussões sobre sexo, sexualidade e gênero na Educação Básica, ocultas nas grades curriculares e abordadas nos programas educacionais na perspectiva biologista. É por essa carência que o autor propõe a discussão em um colégio pré-universitário, a partir de duas cenas do filme Problemas Femininos (Female Trouble), dirigido pelo cineasta estadunidense John Waters (1946), em 1974. Identifica sua perspectiva teórica como sendo os estudos feministas e a teoria queer, levando em consideração autores como Belidson Dias (2011), Guacira Lopes Louro (2010), Paul Beatriz Preciado (2010). O autor afirma que a teoria queer transcende os estudos gays e lésbicos se apropriando e reconstruindo suas ideias, assim como das diversas contribuições dos feminismos, principalmente diante do conceito de gênero, aparato prático e discursivo social, pelo qual homens e mulheres são diferenciados, não se fixando em determinados grupos identitários. Conclui que, além das dificuldades de abordagem da temática, a inserção deste tema na educação também se deve a dificuldade do contexto escolar em dialogar com as perspectivas das e dos estudantes e suas variadas experiências culturais e anseios.

Como procedimento metodológico, Silva (2008) adota o feminismo para interpretar o filme Má Educação, dirigido pelo cineasta espanhol Pedro Almodóvar (1949), em 2004. Considera como metodologia feminista a leitura realizada por Laura Mulvey, sobre o prazer visual e o cinema narrativo, fundamentada na Psicanálise. Mulvey (1983) observa que ainda há um abismo em relação às questões importantes para o inconsciente feminino, irrelevantes para a teoria falocêntrica; porém, a teoria psicanalítica pode ampliar a compreensão do status quo da ordem patriarcal na qual estamos presas. A análise de Silva (2008) focaliza duas personagens do filme: a travesti Zahara e o ator Juan. Conclui que Pedro Almodóvar realiza uma paródia do feminino, apesar de essas personagens funcionarem como pontos reflexivos no filme, por serem representadas de um modo transgressor e remeterem ao estereótipo da mulher fatal, introduzido nas narrativas de detetives da literatura de ficção criminal estadunidense, influenciando os filmes noirs das décadas de 1940 e 1950.

A interpretação do feminino no painel $O$ Reinado do Sol, do artista paraibano Flávio Tavares (1934), produzido no ano de 2008, por encomenda da Prefeitura Municipal de João Pessoa (PB), é o centro da discussão de Stanick (2017). A autora opta por uma abordagem histórica do feminismo mencionando que não há um movimento unívoco e totalizante, mas vários feminismos. Discute aspectos visuais 
tanto da obra mencionada quanto do vocabulário plástico e poético do artista, que, para a autora, transita pela dicotomia barroca, os modernismos latino-americanos e os regionalismos, com ênfase no movimento armorial. Destaca, ainda, a necessidade de se refletir sobre como podem ocorrer as significações de poder e gênero nas imagens da arte e como estas também podem construir a memória imagética de uma cidade.

A fotografia como possibilidade de interpretação e análise da produção de gênero é o cerne da discussão da tese de Ribeiro (2017). A autora analisa duas coleções fotográficas: a coleção privada da arquivista goiana Marilda de Godoi (1924 - 2011) e a coleção de domínio público intitulada Coleção Iconográfica Marilda de Godoi, sob guarda do Instituto de Pesquisa História do Brasil Central (IPEHBC). Defende a tese de que a imagem fotográfica, como artefato resultante da interação social, produz sentidos articulados em narrativas visuais. Na análise das imagens desse acervo, Ribeiro (2017) focalizou as representações dos corpos, disciplinados ou não, de acordo com condutas e normas de seu tempo histórico, a partir de gestos, jeitos, olhares, poses fotográficas, indumentárias, escolhas dos fotógrafos, como enquadramento e cenário. Conclui que os retratos das duas coleções corroboram com os regimes de visualidade que constituem um sistema de regras, estabelecendo os modos de ver e representar visualmente o mundo, e orientando as relações de gênero, os papéis sociais e as relações interpessoais e familiares.

\section{Conclusão}

Após o estudo realizado, podemos concluir que a discussão dos feminismos está presente e se reconhece nos Programas de Pós-Graduação em Artes Visuais, indicando um crescimento quantitativo a partir do ano de 2015. Consideramos que, apesar da expansão apreciada, ainda é uma discussão que se estabelece timidamente, levando em conta as mais de quatro décadas que artistas e críticas, inspiradas nos feminismos, vêm trabalhando para que o sistema da arte considere, de fato, todas as variáveis que constituem as marcações da diferença, como gênero, raça e sexualidade, com o objetivo de torná-lo menos excludente.

Em relação aos feminismos, a produção acadêmica localizada não reconhece a especificidade da categoria mulher, uma condição feminina universal, nem uma estética e ou estilo feminista, mas sinaliza a pluralidade. Foram indicados feminismos que não se ocupam apenas do sexismo, mas apontam para as diversas opressões sociais. Nesses trabalhos, as abordagens históricas do movimento feminista remarcam como os estudos de gênero permitiram questionar o conceito de mulher determinada biologicamente e ampliar as reivindicações para os corpos dissidentes. São trabalhos motivados por uma epistemologia da diferença, para a qual o mundo, e o conhecimento que sobre ele se produz, não se reduz à lógica que parte da identidade de um suposto sujeito universal, mas de subjetividades mais 
ou menos constrangidas por práticas disciplinadoras e de controle, por discursos e saberes instituintes, inseridas em complexas relações sociais, que rompem com um enquadramento conceitual normativo de gênero e sexualidade. Uma epistemologia que valoriza categorias plurais, múltiplas, pois o mundo manifesta-se nas diferenças e ganha sentido por meio de múltiplas matrizes de entendimentos, em olhares que se querem facetados e não cristalizam uma representação essencialista.

São poéticas visuais que incluem problemas que tratam de si, que contam suas histórias e de artistas antepassadas, para compreender práticas opressivas e as inúmeras formas de estereótipos. São leituras sobre os silenciamentos, a falta de reconhecimento social da produção artística de mulheres e os caminhos da criação artística como empoderamento das subjetividades. Essas pesquisadoras indicam como questão urgente a produção de mais estudos na área de Artes Visuais que visibilizem e legitimem as produções artísticas feitas por mulheres brasileiras e latino-americanas. Constatam o investimento das mulheres pesquisadoras sobre as antepassadas para a elaboração de uma genealogia feminina, tecendo uma costura de memórias sobre o protagonismo das artistas. Indicam que a participação empoderada dessas agentes - artistas, curadoras, professoras, críticas - podem engendrar outras formulações de estruturas de poder, representações e apresentações do feminino em um discurso menos binário.

Notamos que as artistas, impulsionando a poética das pesquisadoras e ou suas leituras sobre essa produção, apresentam um perfil muito próximo ao das militantes feministas brasileiras das décadas de 1970 e 1980, brancas, das camadas médias e intelectualizadas, com acesso ao circuito artístico. No estudo realizado a partir dos 35 trabalhos analisados, encontramos uma evidente quebra do princípio da igualdade de representação a partir das variáveis gênero e raça. Em um país como o Brasil não seria uma questão de pensar em incluir minorias no sistema da arte e seus ensinos, pois, de acordo com a Pesquisa Nacional por Amostra de Domicílio Contínua (PNAD Contínua), do Instituto Brasileiro de Geografia e Estatística (IBGE), de 2018 , a população negra representa $55,8 \%$ da população brasileira e 54,9\% da força de trabalho, sem falar nos flutuantes dados referentes às populações indígenas. Sem dúvida, os trabalhos que fizeram parte deste estudo revelam o investimento das pesquisadoras para a reescritura da História da Arte do Brasil, pavimentando a ideia da criação de uma genealogia feminina; contudo, infelizmente, essa genealogia ainda continua excluindo as mulheres indígenas, negras e trans dessa narrativa.

A análise desses trabalhos também nos permitiu vislumbrar algumas problematizações ainda ausentes e sinalizar possíveis percursos de investigação como: a naturalização do feminino na produção artística; leituras da produção artística de mulheres indígenas, negras e trans; a recepção crítica e legitimação da produção artística de mulheres brancas, indígenas, negras e trans; o acesso e o sucesso de mulheres brancas, indígenas, negras, trans na formação em artes; a participação de mulheres brancas, indígenas, negras, trans nos circuitos de exibição e comercialização da produção artística; as assimetrias dos acervos, da gestão dos espaços culturais e da difusão do conhecimento artístico; as políticas culturais para 
a promoção da igualdade; as iniciativas de instituições culturais que nos fazem ver as desigualdades do patriarcado na arte e na educação; o estudo de acervos, discursos expográficos e mediações que valorizem a produção artística de mulheres brancas, indígenas, negras, trans. São problematizações que demandam um esforço coordenado de pesquisa entre os vários Programas de Pós-graduação em Arte Visuais, para fazer frente às desigualdades de gênero, raça, sexualidade e visibilizar a exclusão que sempre favoreceu aos homens brancos no sistema da arte.

\section{Referências}

ADICHIE, Chimamanda Ngozi. (2018). Sejamos Todos Feministas. São Paulo: Companhia de Letras.

AKOTIRENE, Carla. (2018). O que é interseccionalidade? Belo Horizonte: Letramento.

ALMEIDA, Flavia Leme de. (2009). Mulheres recipientes: recortes poéticos do universo feminino nas artes visuais. Dissertação. Programa de Pós-graduação em Artes. Instituto de Artes. Universidade Estadual Paulista Júlio de Mesquita Filho (UNESP).

ALMEIDA, Flavia Leme de. (2018). Desvios do barro: raízes culturais, feminismo e rituais nas poéticas de mulheres artistas da cena contemporânea latino-americana. Tese Programa de Pós-graduação em Artes. Instituto de Artes. Universidade Estadual Paulista Júlio de Mesquita Filho (UNESP).

ALMEIDA, Isadora Maríllia de Moreira. (2018). Mulheres artistas: apontamentos sobre perspectivas e experimentações possíveis. Dissertação Programa de Pós-graduação em Artes. Instituto de Artes e Design. Universidade Federal de Juiz de Fora (UFJF).

ALVES, Branca Moreira; PITANGUY, Jacqueline. (1991). O que é feminismo. São Paulo: Editora Brasiliense.

AMARAL, Aracy A. (2006). Textos do Trópico de Capricórnio: Artigos e ensaios (19802005) v. 2. São Paulo: Editora 34.

ANGELOU, Maya. (2018). Mamãe E eu E mamãe. Rio de Janeiro: Rosa dos Tempos.

ANICETO, Lara Nicolau. (2018). Remexa minhas entranhas: poéticas de um feminino monstruoso. Dissertação. Programa de Pós-graduação em Artes. Instituto de Cultura e Arte. Universidade Federal do Ceará Fortaleza (UFC).

ANZALDÙA, Gloria. (2009). “Como domar uma língua selvagem”. Cadernos de Letras da UFF, n.. 39, p. 297-309,. 
ARRUDA, Lina Alves. (2013). Estratégias desconstrutivas: a crítica feminista da representação. Dissertação. Programa de Pós-graduação em Artes Visuais. Universidade de São Paulo (USP).

BARBOSA, Ana Mae. (2010). "Uma questão de política cultural: mulheres artistas, artesãs, designers e arte/educadoras". In: 19ํㅡㄹ ENCONTRO DA ASSOCIAÇÃO NACIONAL DE PESQUISADORES EM ARTES PLÁSTICAS. Cachoeira (BA), 20 a 25/09/2010.

BARDIN, Laurence. (1979). Análise de conteúdo. São Paulo: Edições 70.

BARROS, Roberta. (2016). Elogio ao toque ou como falar de arte feminista à brasileira. Rio de Janeiro: Relacionarte.

BEAUVOIR, Simone de. (1970). Segundo sexo. São Paulo: Difel.

BENHABIB, Seyla. (2006). El ser y el otro e la ética contemporánea: Feminismo, comunitario y pós-modernismo. Barcelona: Editoral, Gedisa.

BESSE, Susan K. (1999). Modernizando a Desigualdade: Reestruturação da Ideologia de Gênero no Brasil, 1914-1940. São Paulo: EDUSP.

BORTOLIN, Rosana. (2006). Ninho, casa e corpo. Dissertação Mestrado. Escola de Comunicação e Artes da Universidade de São Paulo. São Paulo.

BRAIDOTTI, Rosi. (2002). "Diferença, diversidade e subjetividade nômade”. Labrys, estudos feministas, n.1-2, p. 1-16, jul.- dez.

BRANCO CORNISH, Patricia. (2018). Artistas mulheres na ditadura brasileira: os casos de Wanda Pimentel e Teresinha Soares. Dissertação Programa de Pós-graduação Interunidades em Estética e História da Arte. Universidade de São Paulo (USP).

BUTLER, Judith. (2003). Problemas de gênero: feminismo e subversão da identidade. Rio de Janeiro, RJ. Civilização Brasileira.

CAO, Marián L. F. (1991). “Arte, feminismo y posmodernidad: apuntes de lo que viene”. Arte, Individuo y Sociedad, n. 4, p. 103-110.

CARNEIRO, Aparecida Sueli. (2005). A Construção do Outro como Não-Ser como fundamento do Ser. São Paulo: USP/Feusp. 
CARNEIRO, Sueli.(2001). "EnegreceroFeminismo”.In:SEMINÁRIOINTERNACIONAL SOBRE RACISMO, XENOFOBIA E GÊNERO. Durban, África do Sul, em 27 e 28 de agosto.

CASTAÑEDA DEMESA, Itandehuy. (2019) Abordagens das práticas comunitárias em espaços públicos por meio da poesia têxtil. Dissertação. Programa de Pós-graduação em Arte e Cultura Visual, Faculdade de Artes Visuais, Universidade Federal de Goiás (UFG).

CASTRO, Panmela Silva. (2013). A arte de Anarkia Boladona e outras questões sobre o graffiti. Dissertação. Programa de Pós-graduação em Artes. Universidade do Estado do Rio de Janeiro (UERJ).

CHICAGO, Judy. (2017). "A mulher como artista”. In. PEDROSA A.; MESQUITA, A. (orgs.). Histórias da sexualidade. São Paulo: MASP.

COSTA, Ana Alice Alcantara. (2009). "O feminismo brasileiro em tempos de Ditadura militar”. Labrys, Revista Estudos Feministas, jan./dez..

COUTINHO, Andrea Senra; LOPONTE, Luciana Gruppelli. (2015) "Artes Visuais e feminismos: implicações pedagógicas". Estudos Feministas, 23(1): 312, p. 181-190, jan.abr.

DAVIS, Angela. (2017). Mulheres, cultura e política. São Paulo: Boitempo.

DE MARCO, Edina; SCHMIDT, Simone Pereira. (2003). "Além de uma tela só para si”. Revista Estudos Feministas, 11, (1), jan..

DE MARTINO, Marlen Batista. (2009). Narrativas do eu: confissões na arte contemporânea - o corpo como diário. Tese. Programa de Pós-Graduação em Artes Visuais, Instituto de Artes, Universidade Federal do Rio Grande do Sul (UFRGS).

DIAS, Belidson. (2011). O i/mundo da cultura visual. Brasília: Editora UnB.

DIMAMBRO Nadiesda. (2018). Imagens de Gretta Sarfaty: fotografia, performance e gênero. Dissertação. Programa de Pós-graduação Interunidades em Estética e História da Arte. Universidade de São Paulo (USP).

GALLO, Marina Didier Nunes. (2015). Francesca Woodman e o lugar de onde eu me olho. Dissertação. Programa Associado de Pós-graduação em Artes Visuais UFPB/ UFPE. 
GARCIA, Maryori Katherine Cabrita. (2019). Amatória: práticas artísticas de uma feminista que reescreveu uma parte da memória líquida de seu corpo. Dissertação. Programa de Pós-Graduação em Artes, Instituto de Ciências da Arte, Universidade Federal do Pará, (UFPA).

GIUNTA, Andrea. (2018). Feminismo y arte latinoamericano. Buenos Aires: Siglo XXI Editores.

GONÇALVES, Karla Elizabeth da Silva. (2018). Depois da mulher: fotografia expandida e subjetividades na emancipação do feminino. Dissertação. Programa Associado de Pós-graduação em Artes Visuais UFPB/UFPE.

GRILL, Nathalia Muswieck. (2018). Anônimas: encontros com artistas mulheres como disparador da poética. Dissertação. Programa de Pós-Graduação em Artes Visuais. Centro de Artes. Universidade Federal de Pelotas (UFPel).

GROSENICK, Uta. (org.) (2005). Mulheres Artistas: nos séculos XX e XXI. São Paulo: Taschen.

HARAWAY, Donna J. (200o). "Manifesto Ciborgue. Ciência, tecnologia e feminismosocialista no final do século XX”. In: TADEU, T. Antropologia do Ciborgue. Belo Horizonte: Autêntica editora.

HOLLANDA, Heloisa Buarque de. (org.). (2018). Explosão feminista: arte, cultura, política e universidade. São Paulo: Companhia das Letras

HOLLANDA, Heloisa Buarque de. (org.) (1994) Tendências e impasses: O feminismo como crítica da cultura. Rio de Janeiro: Editora Rocco.

hooks, bell. (2018). O feminismo é para todo mundo: políticas arrebatadoras. Rio de Janeiro: Rosa dos Tempos.

IÓRIO, Alessandra. (2017). Estranho feminino. Dissertação. Programa de Pósgraduação em Artes. Instituto de Artes. Universidade Estadual Paulista Júlio de Mesquita Filho (UNESP).

JONES, Amelia. (2011). "Generando problemas: las artistas feministas ponen en escena el sexo femenino”. Youkalai, Madrid, n. 11, p. 46-54.

LAURETIS, Teresa de. (1994). "A Tecnologia Do Gênero". In: HOLLANDA, H. B. de. Tendências E Impasses. Rio de Janeiro: Roxo. 
LOURO, Guacira Lopes. (2010). "Currículo, gênero e sexualidade: o normal, o diferente e o excêntrico”. In: LOURO, G. L.; NECKEL, J. F.; GOELLNER, S. V. (orgs.). Corpo, gênero e sexualidade: um debate contemporâneo na educação. Petrópolis: Vozes.

LOURO, Guacira. (2004). Um corpo estranho. Belo Horizonte: Autentica.

MADEIRA, Angélica. (2016). Arte e vida social: pesquisas recentes no Brasil e na França. Marseille: OpenEdition Press.

MAFRA, Juliana Silveira. (2017). O amargo humor da arte contemporânea. Tese. Programa de Pós-Graduação em Artes. Escola de Belas Artes. Universidade Federal de Minas Gerais (UFMG).

MARCHI, Salette Mafalda Oliveira. (2009). Presenças do corpo feminino na arte: aproximações a partir de Orlan. Dissertação. Programa de Pós-Graduação em Artes Visuais. Centro de Artes e Letras. Universidade Federal de Santa Maria (UFSM).

MARQUES FILHO, Adair. (2007). Arte e cotidiano: experiência homossexual, teoria queer e educação. Dissertação. Programa de Pós-graduação em Arte e Cultura Visual, Faculdade de Artes Visuais, Universidade Federal de Goiás (UFG).

MATTIOLLI, Isadora Buzo. (2017). O corpo como questão: relações entre feminismos e arte contemporânea no Brasil. Dissertação. Programa de Pós-Graduação em Artes Visuais, Instituto de Artes, Universidade Federal do Rio Grande do Sul (UFRGS).

MAYAYO, Patrícia. (2003). História de mujeres, historias del arte. Madrid: Ediciones Cátedra.

MAYER, Claudia (org.). (2017). Ciberfeminismo: Tecnologia e Empoderamento. União da Vitória: Monstro dos Mares.

MAYER, Mónica. (1999). “De la vida y el arte como feminista”. Paradoxa, n.8.

MORAES, Alice Ferry de; OLIVEIRA, Telma Maria de. (2010). "Experiências relacionadas ao levantamento de teses e dissertações”. Informação E Sociedade: Estudos, 20 (1), p. 73-81, jan. - abr.

MULVEY, Laura. (1983). "Prazer Visual e Cinema Narrativo”. In: XAVIER, I.(org.). A Experiência do Cinema: antologia. Rio de Janeiro: Graal.

NOCHLIN, Linda. (2016). Por que não houve grandes mulheres artistas? São Paulo: Edições Aurora. 
OLIVEIRA, Alex Mateus Santos de. (2014). Uma reflexão sobre questões de gênero em uma escola pública na cidade de Goiânia através da personagem Dawn Davenport em duas cenas do filme Problemas Femininos. Dissertação. Programa de Pós-graduação em Arte e Cultura Visual, Faculdade de Artes Visuais, Universidade Federal de Goiás (UFG).

PACHECO, Mirele de Oliveira. (2019). Arte, redes sociais e pós-internet: a produção de Aleta Valente, Andressa Ce. e Laís Pontes. Dissertação. Programa de Pós-Graduação em Artes Visuais, Instituto de Artes, Universidade Federal do Rio Grande do Sul (UFRGS).

POLLOCK, Griselda. (2013). Visión y diferencia: Feminismo, feminidad e historias del arte. Buenos Aires: Fiordo.

PRECIADO, Paul Beatriz. "La sexualidad es como las lenguas: Todos podemos aprender varias”. El País, Espanha, jun. 2010.

PRECIADO, Paul Beatriz. (2008). Testo Yonqui. Madrid: Espasa.

PRIORE, Mary Del (org). (2007). História das Mulheres no Brasil. São Paulo: Contexto.

RAGO, Margareth. (1998). "Epistemologia feminista, gênero e história”. In: PEDRO, J. M.; GROSSI, M. P.. (orgs.) Masculino, feminino, plural: gênero na interdisciplinaridade. Florianópolis, Ed. Mulheres.

REILLY, Maura. (2019). Activismo en el mundo del arte: hacia una ética del comisariado artístico. Madrid: Alianza Editorial.

RIBEIRO, Djamila. (2017). O que é lugar de fala?. Belo Horizonte: Letramento.

RIBEIRO, Rafaella Sudário. (2017). As caixas de memórias de Marilda de Godoi: arquivo, visualidade dos corpos e poder (1889 - 1969). Tese. Programa de Pós-graduação em Arte e Cultura Visual, Faculdade de Artes Visuais, Universidade Federal de Goiás (UFG).

RIBEIRO, Vinicios Kabral. (2012). Engordurando o Mundo: o corpo de Fernanda Magalhães e as poéticas da transgressão. Dissertação. Programa de Pós-graduação em Arte e Cultura Visual, Faculdade de Artes Visuais, Universidade Federal de Goiás (UFG).

RICHARD, Nelly. (2002). Intervenções Críticas: Arte, Cultura, Gênero e Política. Belo Horizonte: Editora UFMG. 
RODRIGUES, Wladimir Wagner. (2010). As mulheres de Klaxon: o universo feminino a partir dos modernistas. Dissertação. Programa de Pós-graduação em Artes. Instituto de Artes. Universidade Estadual Paulista Júlio de Mesquita Filho (UNESP).

ROMERO, Renata Pedrosa. (2003). Corpo, casa cidade. Dissertação. Escola de Comunicação e Artes da Universidade de São Paulo - CAP/ECA/USP.

ROSLER, Martha. (2011). "La figura del artista”. Youkalai, Madrid, n. 11, p. 5-14.

RUÍDO, Maria. (2005). "La representación de la violencia/ la violencia de la representación: De Jack el Destripador a Ciudad Juárez, pasando por la pantalla de la tv”. In: CONGRESO “MUJERES JÓVENES: ¿LOS NUEVOS FEMINISMOS?”. Fundación Isonomía. Castellón, 14- 16 de septiembre.

SANTOS, Camila Matzenauer dos. (2019). O corpo feminino como metáfora do tempo em performance arte. Dissertação. Programa de Pós-Graduação em Artes Visuais. Centro de Artes e Letras. Universidade Federal de Santa Maria (UFSM).

SANTOS, Dyana dos. (2019). Crisálidas: interlocuções entre Roupa de Artista, Feminismo e Computação Vestível. Dissertação Programa de Pós-Graduação em Artes. Escola de Belas Artes. Universidade Federal de Minas Gerais (UFMG).

SANTOS, Júlio Cesar. (2014). “...se eu fosse uma flor...”: o cinema como dispositivo tecnopoético produzindo simbólicos identitários de uma mulher negra. Tese. Programa de Pós-graduação em Arte e Cultura Visual, Faculdade de Artes Visuais, Universidade Federal de Goiás (UFG).

SANTOS, Renata Aparecida Felinto dos. (2019). "A pálida História das Artes Visuais no Brasil: onde estamos negras e negros?" Revista GEARTE, 6, (2), p. 341-368, mai.-ago.

SARAIVA, Érica Cristiane. (2017). Visualidades de Luiza Prado: poética da excentricidade. Dissertação. Programa de Pós-graduação em Arte e Cultura Visual, Faculdade de Artes Visuais, Universidade Federal de Goiás (UFG).

SARTI, Cynthia Andersen. (2004). "O feminismo brasileiro desde os anos 1970: revisitando uma trajetória”. Estudos Feministas, 12, p. 35-50, mai.-ago.

SARTI, Cynthia Andersen. (1998). "O início do feminismo sob a ditadura no Brasil: o que ficou escondido” In: XXI CONGRESSO INTERNACIONAL DA Chicago, Illinois, set.

SCAVONE, Lucila. (2008). Estudos de gênero: uma sociologia feminista? Estudos Feministas, 16 (1), p. 173-186. 
SCOTT, Joan Wallach. (1995). "Uma categoria útil de análise histórica”. Educação E Realidade, 20, p. 1-99, jul.- dez.

SEGATO, Rita Laura. (2016). La guerra contra las mujeres. Madrid: Traficante de Sueños.

SILVA, Naira Rosana Dias da. (2008). Representação do elemento narrativo mulher fatal: construção das personagens Zahara e Juan no filme Má Educação, do cineasta espanhol Pedro Almodóvar. Dissertação. Programa de Pós-graduação em Arte e Cultura Visual, Faculdade de Artes Visuais, Universidade Federal de Goiás (UFG).

SILVA, Tarcisio Torres. (2013). Estéticas políticas da tela: ativismo e o uso da imagem em redes de comunicação digital. Tese. Programa de Pós-graduação em Artes Visuais. Instituto de Artes. Universidade Estadual de Campinas (UNICAMP).

SIMIONI, Ana Paula Cavalcanti. (2008). Profissão Artista: pintoras e escultoras acadêmicas brasileiras. São Paulo: Editora da Universidade de São Paulo: FAPESP.

SIMIONI, Ana Paula. (2006). "Eternamente Amadoras: Artistas brasileiras sobre o olhar da crítica (1885-1927)”. In: FABRIS, A. (org.). Crítica e Modernidade. São Paulo: ABCA; Imprensa Oficial do Estado de São Paulo.

SONTAG, Susan. (1987). Contra a interpretação. Porto Alegre: L\&PM Editores.

SOUSA, Juliana Padilha. (2019). Tramas invisíveis: bordado e a memória do feminino no processo criativo. Dissertação. Programa de Pós-Graduação em Artes, Instituto de Ciências da Arte, Universidade Federal do Pará, (UFPA).

SOUZA, Karenn de Amorim e. (2019). Desestabilizando o prazer visual: uma análise da representação da mulher na obra de Paula Rego. Dissertação Programa de PósGraduação em Artes. Centro de Artes. Universidade Federal do Espírito Santo (UFES).

SOUZA, Silvia Amelia Nogueira de. (2012). Mulheres, arte e domesticidade: entre a arte feminista e o Dicionário do Lar. Dissertação. Programa de Pós-Graduação em Artes. Escola de Belas Artes. Universidade Federal de Minas Gerais (UFMG).

STANICK, Raquel Cardoso. (2017). Flávio Tavares e a alegoria de uma cidade: Reflexões sobre gênero n'O Reinado do Sol. Dissertação. Programa Associado de Pós-graduação em Artes Visuais UFPB/UFPE.

STUBS, Roberta. (2015). A/r/tografia de um corpo-experiência: arte contemporânea, feminismos e produção de subjetividade. Tese. Universidade Estadual Paulista Júlio de Mesquita Filho, Faculdade de Ciências e Letras de Assis. 
TELES, Maria Amélia de Almeida. (1993). Breve História do Feminismo no Brasil. São Paulo: Brasiliense.

TRIZOLI, Talita. (2018). Atravessamentos feministas: um panorama de mulheres artistas no Brasil dos anos 6o/70. Tese. Programa de Pós-graduação em Educação. Faculdade de Educação, Universidade de São Paulo, São Paulo.

TRIZOLI, Talita. (2011). Trajetórias de Regina Vater: Por uma crítica feminista da arte brasileira. Dissertação. Programa de Pós-graduação Interunidades em Estética e História da Arte. Universidade de São Paulo (USP).

TVARDOVSKAS, Luana Saturnino. (2015). Dramatização dos corpos. Arte contemporânea e crítica feminista no Brasil e na Argentina. São Paulo: Editora Intermeios.

VICENTE, Filipa Lowndes. (2012). A arte sem história: Mulheres e cultura artística (Séculos XVI--XX). Lisboa: Babel.

VILLA, Rocio de la. (2013). "Crítica de arte desde la perspectiva de género". Investigaciones feministas, v. 4, p. 20-23.

XAVIER, Kelly de Oliveira. (2008). Corpo estranho. Dissertação. - Escola de Comunicação e Artes da Universidade de São Paulo - CAP/ECA/USP.

Recebido em 08/03/2020.

Aceito em 13/11/2020. 